\title{
Prognostic values of negative estrogen or progesterone receptor expression in patients with luminal B HER2-negative breast cancer
}

Chansub Park', Kyeongmee Park², Jiyoung Kim³ , Youngjoo Sin, Inseok Park', Hyunjin Cho ${ }^{1}$, Keunho Yang ${ }^{1}$, Byung Noe Bae ${ }^{1}$, Ki Whan Kim', Sookyung Ahn ${ }^{5}$ and Geumhee Gwak ${ }^{1 *}$

\begin{abstract}
Background: The luminal subtype of breast cancer is sensitive to anti-estrogen therapy and shows a better prognosis than that of human epidermal growth factor receptor2 (HER2)-enriched or triple-negative breast cancer. However, the luminal type of breast cancer is heterogeneous and can have aggressive clinical features. We investigated the clinical implications of single hormone receptor negativity in a luminal B HER2negative group.

Methods: We collected luminal B HER2-negative breast cancer data that were estrogen receptor (ER) and/or progesterone receptor (PR) positive, Ki 67 high (>14\%), and HER2 negative and divided them into the ERand PR-positive group and the ER- or PR-negative group. We analyzed the clinical and pathological data and survival according to ER or PR loss.

Results: There were no statistical differences in TNM stage, breast and axillary operative methods, or number of tumors between the ER- and PR-positive group and ER- or PR-negative group. However, the ER- or PR-negative group was associated with older age ( $\geq 45$ years), higher histological grade, lower Bcl-2 expression, and far higher Ki 67 (>50\%). Disease-free survival (DFS) and overall survival (OS) were shorter in the ER- or PR-negative group than that in the ER- and PR-positive group ( $p=0.0038, p=0.0071$ ).

Conclusions: ER- or PR-negative subgroup showed worse prognosis than ER- and PR-positive subgroup in the luminal B HER2-negative group. We could consider the negativity of ER or PR as prognostic marker in luminal B HER2-negative subtype of breast cancer.
\end{abstract}

Keywords: Breast cancer, Estrogen receptor, Luminal B, Progesterone receptor, Prognosis

\section{Background}

Gene expression profiling studies for breast cancer have unveiled that breast cancer has very heterogeneous biological characteristics and at least four molecular distinct subtypes, such as luminal A and B, human epidermal growth factor receptor2 (HER2)enriched, and basal-like subtypes have been identified over the few last decades [1-3]. Personalized therapy

\footnotetext{
*Correspondence: gsrad@hanmail.net

${ }^{1}$ Department of Surgery, Sanggye Paik Hospital, College of Medicine, Inje University, 1342 Dongil-ro, Nowon-gu, Seoul 139-707, Korea

Full list of author information is available at the end of the article
}

according to gene expression profiles for breast cancer patient has been possible to achieve optimal therapeutic effects [4-6]. Many investigators have been making a more progresses for specific clinical conditions in breast cancer patients, such as inflammatory breast cancer, recurrent or metastatic breast cancer, hereditary breast cancer, and basal-like breast cancer [7-11].

The estrogen receptor (ER) and progesterone receptor (PR) are traditional prognostic and predictive factors in breast cancer, and both of them are the mainstays of gene expression profiles to determine 
intrinsic breast cancer subtypes. ER- or PR-positive breast cancers are classified as the luminal subtype, which have a more favorable prognosis and are more responsive to anti-estrogen therapy than that of ERand PR-negative breast cancer [12-14]. However, the luminal subtype of breast cancer is very heterogeneous and occasionally has very aggressive clinical features. Luminal type breast cancer has two biologically distinct subtypes, luminal $\mathrm{A}$ and luminal $\mathrm{B}$, and it is well known that luminal B subtype have higher proliferative characteristics and poorer prognosis than those of luminal A [15].

A number of studies have been reported that luminal B subtype is dramatically distinct from luminal A subtype at the cellular signaling pathway and DNA levels, including growth factor receptors, such as epidermal growth factor receptor (EGFR; HER1) and HER2 as well as its downstream signaling pathway [16]. The St. Gallen International Expert Consensus on the Primary Therapy of Early Breast Cancer 2013 distinguished luminal A-like breast cancer from luminal B-like disease based on immunohistochemical stains of ER, PR, and Ki-67 status without a requirement for molecular diagnostics. Recently, we have figured out the heterogeneity of luminal B HER2-negative group from our consecutive clinical studies, and we wanted to find out which factors affect the disease prognosis that probably related with disease heterogeneity within luminal B subtype. We performed this study to determine the clinical implications of single hormone receptor loss by immunohistochemical (IHC) staining methods in a luminal B HER2-negative group.

\section{Methods}

We collected clinical and pathological data from patients with breast cancer who underwent breast surgery and treatment between January 2004 and December 2014 at Sanggye Paik Hospital. Among the 769 patients, we selected 183 with luminal B HER2negative breast cancers that were ER or PR positive, Ki-67 $>14 \%$, and HER2 negative. We divided them into two groups of the ER and PR positive group and the ER or PR negative group. ER and PR positive group defined as both hormonal receptor showed positive reaction. These two group was compared disease free survival (DFS) and overall survival (OS) between the two groups. We also analyzed the clinical and pathological data of each group, including age, breast and axilla operative methods, tumor type, TNM stage, histological grade, nuclear grade, number of tumors, Ki-67 and $\mathrm{Bcl}-2$ expression, and recurred or metastatic sites. We choose median 45 age, for statistical convenience.

\section{IHC staining for ER, PR, Bcl-2, and Ki 67}

The ER NCL-1-ER-6F11 and PR NCL-L-PGR-312 liquid mouse monoclonal antibodies (Leica Microsystems Inc., Newcastle Upon Tyne, UK) diluted 1:80 with normal goat serum (diluted 1:5 TBS) were used as the primary antibodies for the ER and PR assays, respectively. The secondary antibody was goat antimouse peroxidase conjugated immunoglobulin, and 3,3'-diaminobenzidine tetrahydrochloride (DAB) was used as the chromogen. We scored ER and PR as 0, $1+, 2+$, and $3+$ according to staining intensity with a description of the percentage related to the proportion of stained nuclei in 10 high power fields [17]. We defined ER and PR positivity as any positive score or a percentage greater than zero. We converted the intensity scores and proportion percentages into the Allred score [18]. We determined Allred score 0, 2 is negative, and 3 to 8 is positive [19].

We performed $\mathrm{IHC}$ for $\mathrm{Bcl}-2$ and $\mathrm{Ki}-67$ using the avidin-biotin peroxidase complex method with aminoethylcarbazole as the chromogen and the Vectastain $\mathrm{ABC}$ Elite kit (Vector Laboratories, Burlingame, CA, USA). We counterstained the sections with Mayer's hematoxylin. Sections was incubated in monoclonal mouse anti-human Bcl-2 oncoprotein to assess Bcl-2 (1:100; Dako, Glostrup, Denmark), and brown nuclear immunostaining was examined. Sections were incubated with monoclonal mouse anti-human Ki-67 antigen for the Ki 67 measurements (1:100; Dako), and brown nuclear immunostaining was examined [17]. We defined $\mathrm{Bcl}-2$ overexpression as Bcl-2 intensity over $10 \%$. In addition, low PR expression was defined as Allred score 3, 4. In Ki67, we choose cutoff value at $50 \%$. According to modified 2013 St. Gallen Consensus, high Ki-67 defined 20 \% cutoff. Nevertheless, we wanted to know higher Ki67 labeling index might have association with ER or PR expression.

\section{IHC staining for HER2/neu}

We performed IHC of the HER2/neu protein on 4- $\mu$ mthick paraffin embedded tissue sections on poly-L-lysinecoated slides. After deparaffinization and blocking of endogenous peroxidase, we performed HER2/neu immunostaining using the rabbit anti-human c-erbB-2 oncoprotein as the primary antibody (Dako) at a 1:100 dilution. Binding of the primary antibody was detected using the Dako Quick-Staining, labeled streptavidinbiotin system (Dako, Carpentaria, CA, USA), followed by adding the DAB chromogen. Two pathologists scored each slide according to the manufacturer's recommended criteria in a blinded fashion. We red immunostaining in a semi-quantitative manner and graded as follows: $0,1+, 2+$, and $3+$. We designated intensity scores of 0 or $1+$ as negative expression and $3+$ as positive expression for HER2/neu. We considered a 2+ score 
as equivocal, which was subjected to silver-enhanced in situ hybridization (SISH) analysis [17].

\section{SISH for HER2}

We performed HER2 SISH on the Ventana Benchmark automated instrument (Ventana Medical Systems, Tucson, AZ, USA), according to the manufacturer's protocols for INFORM HER2 DNA and chromosome 17 probes. We performed testing for the HER2 gene and chromosome 17 on sequential sections. Two sections were baked at $60^{\circ} \mathrm{C}$ for $20 \mathrm{~min}$. The HER2 DNA probe was denatured at $95{ }^{\circ} \mathrm{C}$ for $12 \mathrm{~min}$, and hybridization was performed at $52{ }^{\circ} \mathrm{C}$ for $2 \mathrm{~h}$. The chromosome 17 probe was denatured at $95^{\circ} \mathrm{C}$ for $12 \mathrm{~min}$, and hybridization was performed at $44{ }^{\circ} \mathrm{C}$ for $2 \mathrm{~h}$. After hybridization, appropriate stringency washes were performed three times at $72{ }^{\circ} \mathrm{C}$ for the HER2 probe and three times at $59{ }^{\circ} \mathrm{C}$ for the chromosome 17 probe. Both DNP-labeled probes were visualized using a rabbit anti-DNP primary antibody and the ultraView SISH Detection Kit (Ventana). The slides were counterstained with hematoxylin for examination by light microscopy. Evaluation of HER2 gene amplification status was performed in a blinded manner using the ASCO/CAP guidelines [20].

\section{Statistical methods}

We used the chi-square test to analyze the clinicpathologic factors affecting prognosis between the ERor PR-negative group and the ER- and PR-positive group. We analyzed the difference in DFS between the ER- or PR-negative and the ER- and PR-positive groups by the Kaplan-Meier method. A univariate analysis of the clinic-pathologic factors affecting prognosis in both groups was conducted with the log-rank test. We used the Cox multivariate regression model for the multivariate analysis. MedCalc Statistical Software ver. 15.5 software (MedCalc Software, Ostend, Belgium; https://www.medcalc.org; 2015) was used for the statistical analysis. We considered a $p$ value $<0.05$ as statistically significant value.

\section{Results}

We collected 184 luminal B HER2-negative breast cancers from 769 patients with breast cancer. Among them, ER negative observed in four patients and PR negative in 20 patients. Thus, the ER- and PR-positive group included 160 cases and the ER- or PR-negative group had 24. PR-negative group included 20 cases, PR low group had 44, and PR high group had 120.

\section{Univariate and multivariate analyses of the pathologic characteristics according to ER or PR status}

The median age of the patients was 48.5 years in the ER- and PR-positive group and 55.5 years in the ERor PR-negative group. A significant difference between the ER- and PR-positive and ER- or PR-negative groups was detected when we used 45 years as the age cutoff value $(p=0.0336)$. Fifty-five patients (29.9 \%) were TNM stage I, 92 (50.0 \%) were stage II, 33 (17.9 \%) were stage III, and $4(2.2 \%)$ were stage IV. In total, 129 patients (70.1\%) received breastconserving surgery and 55 received mastectomy. Axillary lymph node dissection was performed in 112 patients (60.9\%), sentinel lymph node biopsy in 70 patients $(38.0 \%)$, and an axillary procedure was omitted in 2 patients. No significant differences in TNM stage, operative method, axillary lymph node evaluation method, or number of tumors were observed between the ER- and PR-positive and ER- or PR-negative groups (Table 1).

However, the ER- or PR-negative group was significantly correlated with a lower Bcl-2 $(\leq 10 \%)$ expression $(p=0.0006)$ and a far higher Ki-67 index $(>50 \%)(p=$ $0.0167)$ than those in the ER- and PR-positive group (Table 1). In terms of relapse, bone and liver metastases were significantly more frequent in the ER- or PRnegative group than those in the ER- and PR-positive group ( $p=0.0297, p=0.0093$, respectively) (Table 2 ). The multivariate analysis revealed that Bcl-2 expression $(p=0.0012)$ was significantly related with ER or PR negative, respectively (Table 3 ).

\section{Adjuvant therapies in luminal B HER2-negative breast cancer}

Adjuvant systemic chemotherapy was performed for 133 of the 160 patients in the ER- and PR-positive group (83.1\%) and for 22 of the 24 patients in the ER- or PRnegative group $(91.7 \%)$ The chemotherapy regimens were anthracycline and/or taxane-based, cyclophosphamide/ methotrexate/5-fluorouracil, and cyclophosphamide/vinorelbine/5-fluorouracil.

Adjuvant hormonal therapy was performed for 148 of the 160 patients in the ER- and PR-positive group $(92.5 \%)$ and for 22 of the 24 patients in the ER- or PRnegative group $(91.7 \%)$. A slight difference in the choice of drugs was observed between the two groups. The selective estrogen receptor modulators (SERM), such as tamoxifen and toremifene, were prescribed more frequently in the ER and PR positive than that in the ER- or PR-negative group (62.5 vs. $37.5 \%$ ). In addition, aromatase inhibitors, such as anastrozole and letrozole, were prescribed more frequently in the ER- or PRnegative group than those in the ER- and PR-positive group. (54.2 vs. $30.6 \%)(p=0.0579)$.

In total, 110 (68.7\%) of the 160 patients in the ERand PR-positive group, and 17 (70.8\%) of the 24 in the ER- or PR-negative group received radiation therapy for breast and/or regional axillary lymph nodes (Table 1). 
Table 1 The clinic-pathologic characteristics of luminal B HER2-negative breast cancer

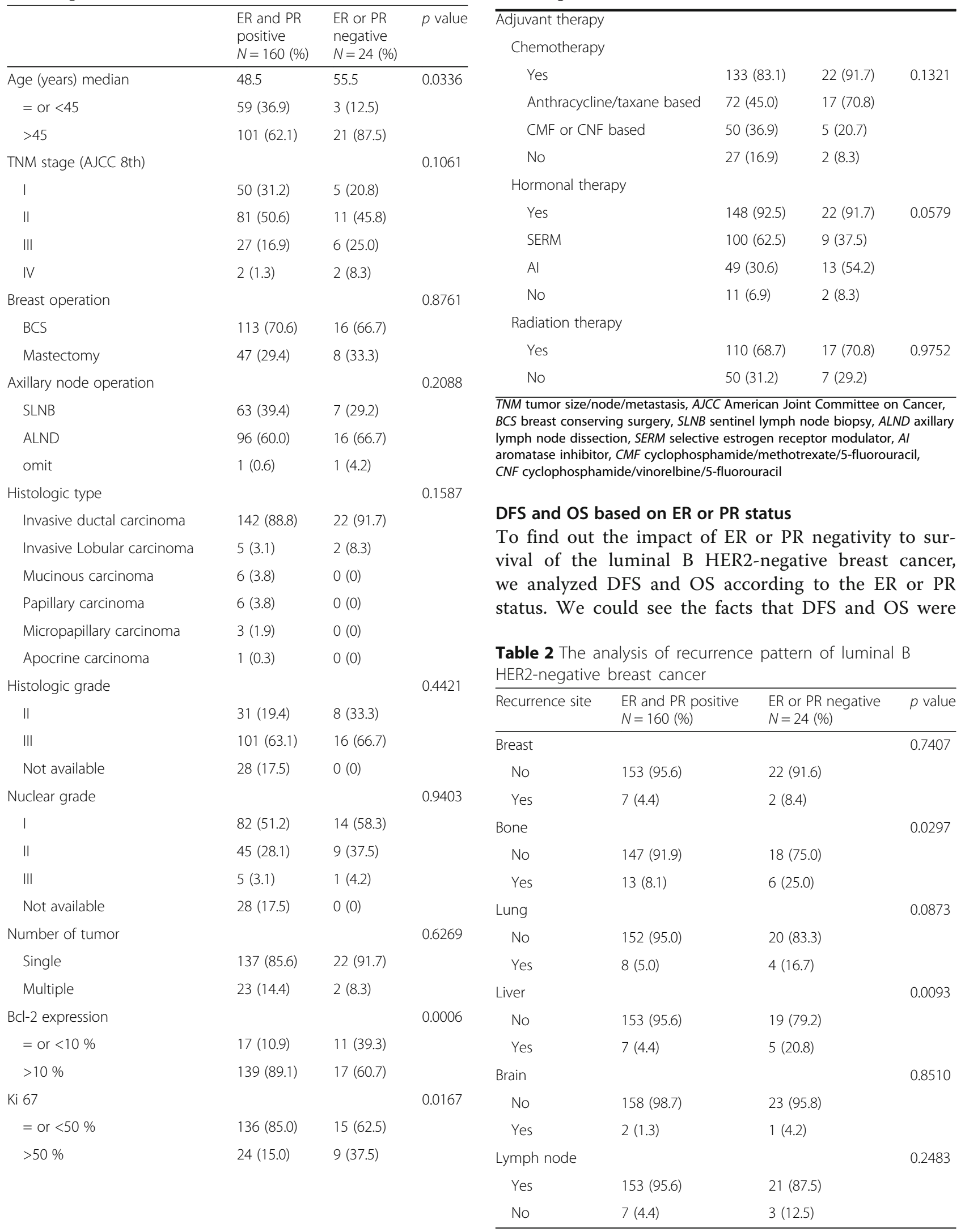

Table 1 The clinic-pathologic characteristics of luminal B HER2-negative breast cancer (Continued)

$$
\text { HER2-negative breast cancer (Continued) }
$$

TNM tumor size/node/metastasis, AJCC American Joint Committee on Cancer, aromatase inhibitor, CMF cyclophosphamide/methotrexate/5-fluorouracil

DFS and OS based on ER or PR status we analyzed DFS and OS according to the ER or PR status. We could see the facts that DFS and OS were

Table 2 The analysis of recurrence pattern of luminal B HER2-negative breast cancer 
Table 3 Multivariate analysis of factors associated with ER or PR negativity

\begin{tabular}{llllll}
\hline Variable & Coefficient & Std. error & Odds ratio & $95 \% \mathrm{Cl}$ & $p$ value \\
\hline Age (median 45) & -0.64939 & 0.50740 & 0.5224 & 0.1932 to 1.4121 & 0.2006 \\
Bcl-2 (cutoff 10\%) & 1.54314 & 0.47871 & 4.6793 & 1.8310 to 11.9580 & 0.0012 \\
Ki 67 (cutoff 50 \%) & -0.70809 & 0.49583 & 0.4926 & 0.1864 to 1.3018 & 0.1533 \\
\hline
\end{tabular}

Cl confidence interval

better in the ER- and PR-positive group than those in the ER- or PR-negative group, and there were statistically significant differences between the two groups ( $p=0.0338, p=0.0119$, respectively) (Fig. 1a, b).

\section{DFS and OS according to negative, low expression, or positive PR status}

We were also interested in whether PR expression level was associated with prognosis. Thus, we divided the PRpositive group into low and high PR expression groups and performed a survival analysis according to PR expression level. The results showed that low PR expression group resulted in better DFS $(p=0.0005)$ and OS $(p<0.0001)$ than those of the negative PR expression group but was worse than that of the high PR expression group (Fig. 1c, d).

\section{DFS and OS according to $\mathrm{Bcl}-2$ expression status}

As we mentioned above, negative ER or PR expression group showed shorter DFS and OS than positive ER and PR expression group. In our multivariate analysis, Bcl-2 expression also was a prognostic factor related to ER or PR expression status. When we analyzed DFS and OS according to the expression status of $\mathrm{Bcl}-2$, lower $\mathrm{Bcl}-2$ expression has relation with better DFS $(p=0.0007)$ and OS $(p<0.0001)$ (Fig. 2).

\section{Discussion}

The ER and PR are expressed in approximately 60 70\% of breast carcinomas, suggesting that steroid hormones influence tumor progression [13]. Systematic investigations into the gene expression patterns in human breast tumors have provided the basis for improved molecular taxonomy of breast cancers [21]. Among the four alleged molecular subtypes of breast cancer, the luminal subtype expresses ER and/or PR, which is a prognostic factor and predictive marker for anti-estrogen hormonal therapies, such as SERM or aromatase inhibitors. However, the luminal subtype of breast cancer is very heterogeneous, and its certain subsets have been showing very aggressive characteristics in clinical setting. Sometimes, their prognosis is similar to or worse than that of HER-2-enriched or triple-negative breast cancers [22]. Bardou et al. had worked with breast cancer databases to investigate whether PR status provides additional value to ER status in patients with primary breast cancer. The results indicated that PR status is an independent predictive factor for a benefit from adjuvant anti-estrogen therapy [23].

Our investigators wanted to know the clinical implications of the negativity of ER or PR in luminal HER2negative breast cancer from this study. Our results showed that ER or PR negativity is poor prognostic factors, and disease-free survival and overall survival in the ER- or PR-negative group were shorter than that in the ER- and PR-positive group. We also wanted to know the specific role of each hormonal receptor through the comparison between the ER-negative and PR-negative groups. As a result, the ER-negative group tended to have shorter survival than the PR-negative group. Few studies were conducted on ER-negative and PR-positive breast cancer because of the low incidence of cases. These studies showed that ER-negative and PR-positive breast cancer is associated with older age, higher proliferation, and a worse prognosis [22, 24]. ER-positive and PR-negative tumors differ from ER-negative and PR-positive tumors, as shown by our results. When we analyzed the prognostic value according to the level of PR expression, the low PR expression group showed an intermediate prognosis better than the negative PR and worse than the high PR expression group. Nishimukai et al. reported that low PR expression is associated with prognosis of ER-positive and HER2-negative breast cancer [25], which agrees with our study.

Furthermore, the Arimidex, Tamoxifen, Alone or in Combination (ATAC) trial showed that patients with ER-positive and PR-negative tumors have a higher recurrence rate than those with ER-positive and PR-positive tumors. In a subgroup analysis of ER-positive and PRnegative tumors, the recurrence rate was much higher in the group that received tamoxifen than that in the group that received anastrozole [26, 27]. Growing evidence supports that ER-positive and PR-negative breast cancers are less responsive to SERM than that of ER-positive and PR-positive tumors. Because increased crosstalk between ER and growth factor signaling pathways leads to downregulated PR transcription, blocking the ER completely with aromatase inhibitor could be more effective in patients with ER-positive and PR-negative breast cancer [28]. In our study, we have specified a luminal B HER2-negative breast cancer subgroup to determine whether ER or PR negativity provides additional prognostic value in patients with high risk HER2-negative 


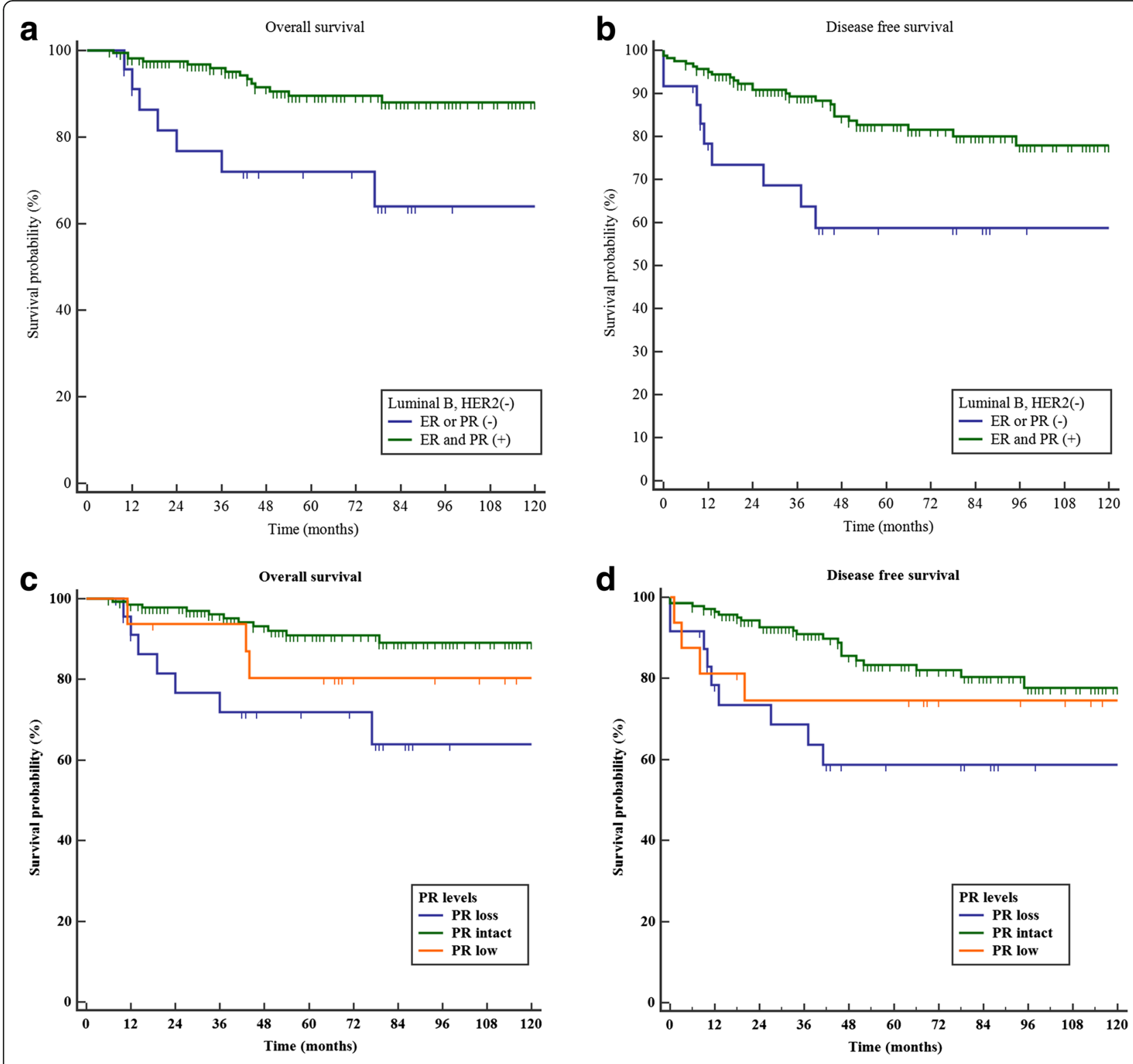

Fig. 1 a Overall survivals of ER- or PR-negative group and ER- and PR-positive group in the luminal B HER-2 negative breast cancer ( $p=0.0119)$. $\mathbf{b}$ Disease-free survivals of ER- or PR-negative group and ER- and PR-positive group in the luminal B HER-2-negative breast cancer $(p=0.0338)$. $\mathbf{c}$ Overall survivals of PR-positive, PR low, and PR-negative group in the luminal B HER-2-negative breast cancer $(p<0.0001)$. d Disease-free survivals of PR-positive, PR low, and PR-negative group in the luminal B HER-2-negative breast cancer $(p=0.0005)$ (Additional file 1)

endocrine-responsive breast cancer. As a result, the ERor PR-negative group showed a higher recurrence rate and decreased OS compared to the ER- and PR-positive group. However, we found no difference when we compared anastrozole to tamoxifen in our study because of the small number of patients.

Several years ago, we had reported the results of study that Bcl-2 may be a potent prognostic factor in patients with luminal subtype of breast cancer [17]. Sivestrini et al. had reported that expression of Bcl-2, an antiapoptotic protein, is associated with low-grade, slowly proliferating, ER-positive breast tumors [29]. There are several previous studies had shown that increased expression of Bcl-2 was associated with improved survival in breast cancer and probability of prognostic role in endocrine-responsive breast cancer [30, 31]. In our current study, we also could see the common results that lower $\mathrm{Bcl}-2$ expression is related with shorter survival and ER or PR negativity, suggesting that Bcl-2 may be a candidate prognostic factor in patients with endocrine-responsive breast cancer. There is a study that when patients were classified into four groups based on 

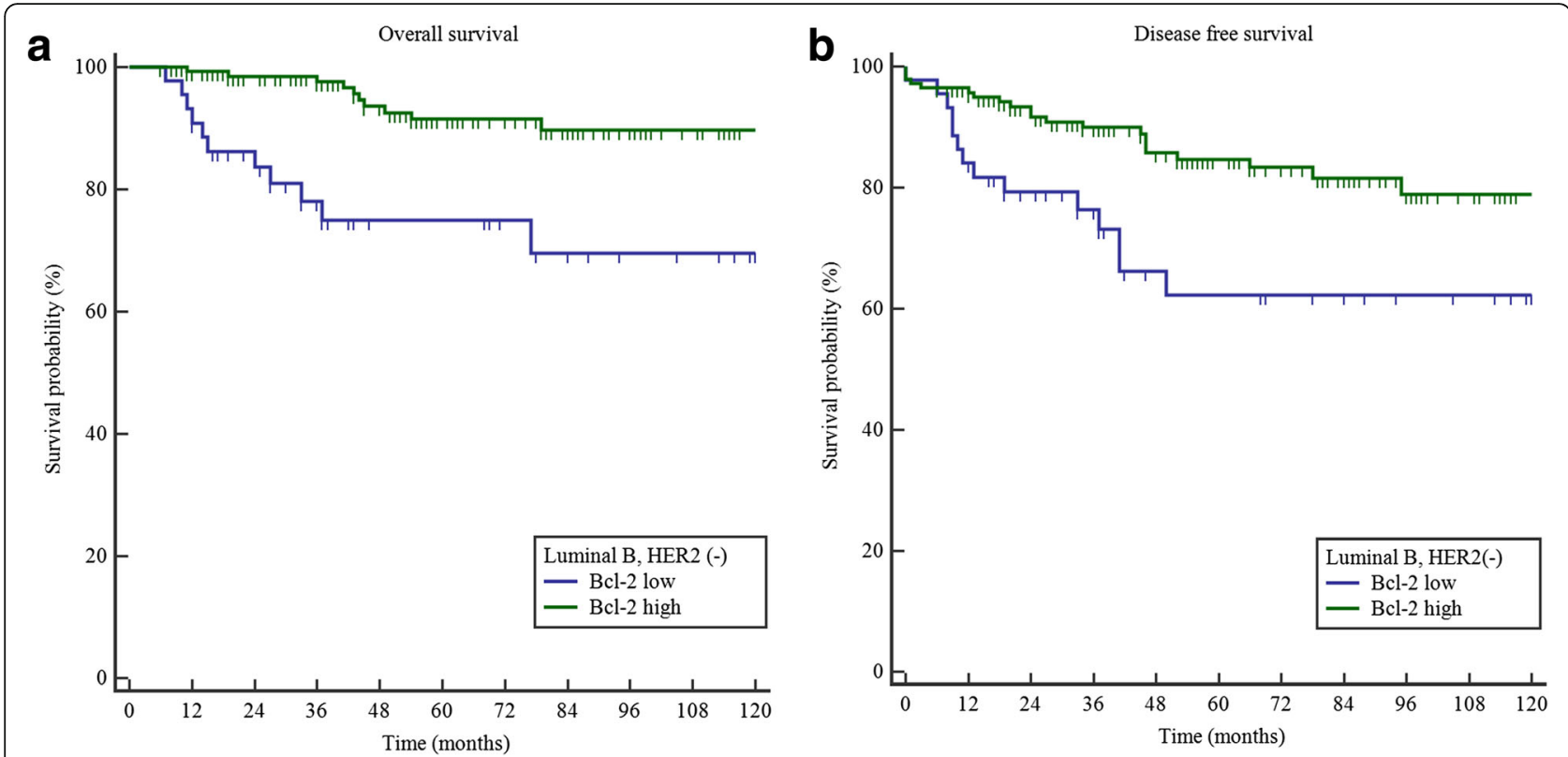

Fig. 2 a Overall survivals of low and high Bcl-2 expression group in the luminal B HER-2-negative breast cancer $(p<0.0001)$. b Disease-free survivals of low and high Bcl-2 expression group in the luminal B HER-2-negative breast cancer ( $p=0.0007)$ (Additional file 1)

HR and HER2 status, more than $10 \%$ of Bcl-2 expression in the HR-positive HER2-negative group resulted in a poorer prognosis, which agrees with our results [32]. We authors cautiously suggest that $\mathrm{Bcl}-2$ expression might have a prognostic role in luminal B HER2negative breast cancer from our current study.

Through the recent studies for gene expression profile in breast cancer, we had an insight for the role of proliferative signatures in breast cancer in terms of prognosis and prediction of response to anti-cancer therapy [33]. Ki-67 expression levels varies throughout the different cell cycle phases, which are low in the G1 and S phases and reaches its peak level in mitosis [34]. The panel of the St Gallen International Expert Consensus on the primary therapy of early breast cancer recommends the use of proliferation markers such as Ki-67 index when physicians decide the appropriate systemic treatment in addition to traditional parameters [35]. However, there are some arguments between investigators to determine the appropriate cutoff values of Ki-67 in terms of prognosis of breast cancer or finding out the most potent subgroup who may get more advantages from anticancer therapy.

Although the role of $\mathrm{Ki}-67$ as a prognostic factor is controversial in breast cancer, many studies have shown a relationship between Ki-67 and HR [25, 36]. When we divided luminal B HER2-negative breast cancer patients into two subgroups according to a Ki-67 level with cutoff $50 \%$, the subgroup with higher Ki-67 (>50\%) was related with the negative ER or PR group. Nishimukai et al. reported that high Ki-67 expression and low PR expression is associated with the prognosis of patients with ER-positive HER2-negative cancers [25], which agrees with our results.

\section{Conclusions}

ER or PR negativities in patients with luminal B HER2negative breast cancer were strongly associated with a poor prognosis. We observed that ER or PR negativities are more frequent in patients with luminal B HER2negative breast cancer who were older than 45 years old, had lower Bcl-2 expression, and a higher Ki 67 index. However, additional studies with large number of patients who are classified to luminal B HER2-negative breast cancer subgroup might reveal the role of ER or PR negativities in breast cancer.

\section{Additional file}

Additional file 1: Result of statistic analysis. (DOCX 389 kb)

\section{Abbreviations}

HER2: Human epidermal growth factor receptor2; ER: Estrogen receptor; PR: Progesterone receptor; DFS: Disease-free survival; OS: Overall survival; EGFR: Epidermal growth factor receptor; IHC: Immunohistochemical; SISH: Silver-enhanced in situ hybridization; SERM: Selective estrogen receptor modulator

\section{Acknowledgements}

Not applicable.

\section{Funding}

This work was supported by 2015 Inje University research grant (R08). Award number: R08

Recipient: Geumhee Gwak 


\section{Authors' contributions}

GHG is the corresponding author and participated in the manuscript editing and data analysis. CSP is the first author and participated in the manuscript editing and data analysis. KMP, JYK, YJS, ISP, HJC, KHY, BNB, KWK, and SKA were involved in reviewing the manuscript and data analysis support. All authors read and approved the final manuscript.

\section{Competing interests}

The authors declare that they have no competing interests.

\section{Consent for publication}

Not applicable.

\section{Ethics approval and consent to participate}

Inje University Sanggye Paik Hospital Institutional review board. IRB File No.: SGPAIK 2015-08-010

\section{Author details}

'Department of Surgery, Sanggye Paik Hospital, College of Medicine, Inje University, 1342 Dongil-ro, Nowon-gu, Seoul 139-707, Korea. ${ }^{2}$ Department of Pathology, Sanggye Paik Hospital, College of Medicine, Inje University, Seoul, Korea. ${ }^{3}$ Department of Diagnostic Radiology, Sanggye Paik Hospital, College of Medicine, Inje University, Seoul, Korea. ${ }^{4}$ Department of Radiologic Oncologist, Sanggye Paik Hospital, College of Medicine, Inje University, Seoul, Korea. ${ }^{5}$ Department of Surgery, Kangnam Sacred Heart Hospital, College of Medicine, Hallym University, Seoul, Korea.

\section{Received: 26 January 2016 Accepted: 31 August 2016}

\section{Published online: 13 September 2016}

\section{References}

1. Prat A, Parker JS, Fan C, Cheang MCU, Miller LD, Bergh J, Chia SKL, Bernard PS, Nielsen TO, Ellis MJ, Carey LA, Perou CM. Concordance among gene expression-based predictors for ER-positive breast cancer treated with adjuvant tamoxifen. Ann Oncol. 2012;23(11):2866-73.

2. Sorlie T, Perou CM, Tibshirani R, Aas T, Geisler S, Johnsen H, Hastie T, Eisen $M B$, van de Rijn M, Jeffrey SS, Thorsen T, Quist H, Matese JC, Brown PO, Botstein D, Lonning PE, Borresen-Dale AL. Gene expression patterns of breast carcinomas distinguish tumor subclasses with clinical implications. Proc Natl Acad Sci U S A. 2001;98(19):10869-74.

3. Weigelt B, Hu Z, He X, Livasy C, Carey LA, Ewend MG, Glas AM, Perou CM, Van't Veer $L$. Molecular portraits and 70-gene prognosis signature are preserved throughout the metastatic process of breast cancer. Cancer Res. 2005:65(20):9155-8.

4. Abramovitz M, Barwick BG, Willis S, Young B, Catzavelos C, Li Z, Kodani M, Tang W, Bouzyk M, Moreno CS, Leyland-Jones B. Molecular characterisation of formalin-fixed paraffin-embedded (FFPE) breast tumour specimens using a custom 512-gene breast cancer bead array-based platform. Br J Cancer. 2011;105(10):1574-81.

5. Ignatiadis M, Singhal SK, Desmedt C, Haibe-Kains B, Criscitiello C, Andre F, Loi S, Piccart M, Michiels S, Sotiriou C. Gene modules and response to neoadjuvant chemotherapy in breast cancer subtypes: a pooled analysis. J Clin Oncol. 2012;30(16):1996-2004.

6. Prat A, Parker JS, Fan C, Perou CM. PAM50 assay and the three-gene model for identifying the major and clinically relevant molecular subtypes of breast cancer. Breast Cancer Res Treat. 2012;135(1):301-6.

7. Iwamoto T, Bianchini G, Qi Y, Cristofanilli M, Lucci A, Woodward WA Reuben JM, Matsuoka J, Gong Y, Krishnamurthy S, Valero V, Hortobagyi GN, Robertson F, Symmans WF, Pusztai L, Ueno NT. Different gene expressions are associated with the different molecular subtypes of inflammatory breast cancer. Breast Cancer Res Treat. 2010;125(3):785-95.

8. Sabatier R, Finetti P, Cervera N, Lambaudie E, Esterni B, Mamessier E, Tallet A, Chabannon C, Extra JM, Jacquemier J, Viens P, Birnbaum D, Bertucci F. A gene expression signature identifies two prognostic subgroups of basal breast cancer. Breast Cancer Res Treat. 2011;126(2):407-20.

9. Tobin NP, Harrell JC, Lovrot J, Egyhazi Brage S, Frostvik Stolt M, Carlsson L, Einbeigi Z, Linderholm B, Loman N, Malmberg M, Walz T, Ferno M, Perou CM, Bergh J, Hatschek T, Lindstrom LS, Hedenfalk I, Brandberg Y, Carstensen J, Egyhazy S, Stolt MF, Skoog L, Hellstrom M, Maliniemi M, Svensson H, Astrom G, Bjohle J, Lidbrink E, Rotstein S, Wallberg B, Carlsson P, Malmstrom $P$, Soderberg M, Umea, Lindh B, Sundqvist M, Malmberg L. Molecular subtype and tumor characteristics of breast cancer metastases as assessed by gene expression significantly influence patient post-relapse survival. Ann Oncol. 2014;26(1):81-8.

10. Mills K, Lee U, Frankenberger C, Yun J, Bevilacqua E, Caldas C, Chin S-F, Rueda OM, Reinitz J, Rosner MR. A prognostic gene signature for metastasisfree survival of triple negative breast cancer patients. PLoS One. 2013;8(12):e82125

11. Van Laere SJ, Ueno NT, Finetti P, Vermeulen P, Lucci A, Robertson FM, Marsan M, Iwamoto T, Krishnamurthy S, Masuda H, van Dam P, Woodward WA, Viens P, Cristofanilli M, Birnbaum D, Dirix L, Reuben JM, Bertucci F. Uncovering the molecular secrets of inflammatory breast cancer biology: an integrated analysis of three distinct affymetrix gene expression datasets. Clin Cancer Res. 2013;19(17):4685-96.

12. Clark GM, Osborne CK, McGuire WL. Correlations between estrogen receptor, progesterone receptor, and patient characteristics in human breast cancer. J Clin Oncol. 1984;2(10):1102-9.

13. Fisher B, Redmond C, Brown A, Wickerham DL, Wolmark N, Allegra J, Escher G, Lippman M, Savlov E, Wittliff J, et al. Influence of tumor estrogen and progesterone receptor levels on the response to tamoxifen and chemotherapy in primary breast cancer. J Clin Oncol. 1983;1 (4):227-41.

14. Valavaara R, Tuominen J, Johansson R. Predictive value of tumor estrogen and progesterone receptor levels in postmenopausal women with advanced breast cancer treated with toremifene. Cancer. 1990; Dec 1(66):2264-9

15. Cheang MCU, Chia SK, Voduc D, Gao D, Leung S, Snider J, Watson M, Davies S, Bernard PS, Parker JS, Perou CM, Ellis MJ, Nielsen TO. Ki67 index, HER2 status, and prognosis of patients with luminal B breast cancer. J Natl Cancer Inst. 2009;101(10):736-50.

16. Creighton CJ. The molecular profile of luminal B breast cancer. Biologics. 2012;6:289-97.

17. Kim H-S, Park I, Cho HJ, Gwak G, Yang K, Bae BN, Kim KW, Han S, Kim H-J, Kim Y-D. Analysis of the potent prognostic factors in luminal-type breast cancer. Journal of Breast Cancer. 2012;15(4):401.

18. Allred D, Harvey J, Berardo M, Clark G. Prognostic and predictive factors in breast cancer by immunohistochemical analysis. Mod Pathol. 1998; Feb(11):155-68

19. Phillips T, Murray G, Wakamiya K, Askaa J, Huang D, Welcher R, Pii K, Allred DC. Development of standard estrogen and progesterone receptor immunohistochemical assays for selection of patients for antihormonal therapy. Appl Immunohistochem Mol Morphol. 2007;15:325-31.

20. Park K, Han S, Kim J-Y, Kim H-J, Kwon JE, Gwak G. Silver-enhanced in situ hybridization as an alternative to fluorescence in situ hybridization for assaying HER2 amplification in clinical breast cancer. Journal of Breast Cancer. 2011;14(4):276

21. Perou CM, Sorlie T, Eisen MB, van de Rijn M, et al. Molecular portraits of human breast tumours. Nature. 2000;406(6797):747-52

22. Park S, Park B-W, Kim TH, Jeon CW, Kang H-S, Choi J-E, Hwang K-T, Kim IC Lack of either estrogen or progesterone receptor expression is associated with poor survival outcome among luminal A breast cancer subtype. Ann Surg Oncol. 2012;20(5):1505-13.

23. Bardou V-J, Arpino G, Elledge RM, Osborne CK, Clark GM. Progesterone receptor status significantly improves outcome prediction over estrogen receptor status alone for adjuvant endocrine therapy in two large breast cancer databases. J Clin Oncol. 2003;21(10):1973-9.

24. Rakha EA, El-Sayed ME, Green AR, Paish EC, Powe DG, Gee J, Nicholson Rl, Lee AHS, Robertson JFR, Ellis IO. Biologic and clinical characteristics of breast cancer with single hormone receptor positive phenotype. J Clin Oncol. 2007:25(30):4772-8.

25. Nishimukai A, Yagi T, Yanai A, Miyagawa Y, Enomoto Y, Murase K, Imamura M, Takatsuka Y, Sakita I, Hatada T, Miyoshi Y. High Ki-67 Expression and low progesterone receptor expression could independently lead to a worse prognosis for postmenopausal patients with estrogen receptor-positive and HER2-negative breast cancer. Clin Breast Cancer. 2015;15(3):204-11.

26. Dowsett M. Retrospective analysis of time to recurrence in the ATAC trial according to hormone receptor status: an hypothesis-generating study. J Clin Oncol. 2005;23(30):7512-7.

27. Singh A, Ali S, Kothari MS, De Bella MT, Smith C, Timms E, Slade MJ, Foxwell BM, Coombes RC. Reporter gene assay demonstrates functional differences in estrogen receptor activity in purified breast cancer cells: a pilot study. Int J Cancer. 2003;107(5):700-6.

28. Cui X. Biology of progesterone receptor loss in breast cancer and its implications for endocrine therapy. J Clin Oncol. 2005;23(30):7721-35. 
29. Silvestrini R, Veneroni S, Daidone MG, Benini E, Boracchi P, Mezzetti M, Di Fronzo G, Rilke F, Veronesi U. The Bcl-2 Protein: a prognostic indicator strongly related to p53 protein in lymph node-negative breast cancer patients. J Natl Cancer Inst. 1994:86(7):499-504.

30. Neri A, Marrelli D, Roviello F, De Marco G, Mariani F, De Stefano A, Megha T, Caruso S, Corso G, Cioppa T, Pinto E. Bcl-2 expression correlates with lymphovascular invasion and long-term prognosis in breast cancer. Breast Cancer Res Treat. 2006;99(1):77-83.

31. Callagy GM, Webber MJ, Pharoah PDP, Caldas C. Meta-analysis confirms $\mathrm{BCL} 2$ is an independent prognostic marker in breast cancer. BMC Cancer. 2008:8(1):153

32. Seong M-K, Lee J-Y, Byeon J, Sohn Y-J, Seol H, Lee J-K, Kim E-K, Kim H-A, Noh WC. BCl-2 is a highly significant prognostic marker of hormonereceptor-positive, human epidermal growth factor receptor-2-negative breast cancer. Breast Cancer Res Treat. 2015;150(1):141-8.

33. Dai H, van't Veer L, Lamb J, He YD, Mao M, Fine BM, Bernards R, van de Vijver M, Deutsch P, Sachs A, Stoughton R, Friend S. A cell proliferation signature is a marker of extremely poor outcome in a subpopulation of breast cancer patients. Cancer Res. 2005;65(10):4059-66.

34. Gerdes J, Schwab U, Lemke H, Stein H. Production of a mouse monoclonal antibody reactive with a human nuclear antigen associated with cell proliferation. Int J Cancer. 1983:31(1):13-20.

35. Goldhirsch A, Ingle JN, Gelber RD, Coates AS, Thürlimann B, Senn HJ. Thresholds for therapies: highlights of the St Gallen International Expert Consensus on the primary therapy of early breast cancer 2009. Ann Oncol. 2009;20(8):1319-29.

36. Andre F, Arnedos M, Goubar A, Ghouadni A, Delaloge S. Ki67-no evidence for its use in node-positive breast cancer. Nat Rev Clin Oncol. 2015;12(5):296-301.

\section{Submit your next manuscript to BioMed Central and we will help you at every step:}

- We accept pre-submission inquiries

- Our selector tool helps you to find the most relevant journal

- We provide round the clock customer support

- Convenient online submission

- Thorough peer review

- Inclusion in PubMed and all major indexing services

- Maximum visibility for your research

Submit your manuscript at www.biomedcentral.com/submit 